\title{
ALL KINDS OF PEOPLE, ALL KINDS OF WAYS
}

By

Klasha Fernandes, BA, University of Toronto, 2015, MFA, Ryerson University, 2019

\author{
A MRP \\ presented to Ryerson University \\ In partial fulfillment \\ of the requirements for the degree of \\ Master of Fine Arts \\ In the program of \\ Documentary Media \\ Toronto, Ontario, Canada, 2019 \\ (C) Klasha Fernandes, 2019
}




\section{AUTHOR'S DECLARATION}

I hereby declare that I am the sole author of this MRP. This is a true copy of the MRP, including any required final revisions.

I authorize Ryerson University to lend this MRP to other institutions or individuals for the purpose of scholarly research.

I further authorize Ryerson University to reproduce this MRP by photocopying or by other means, in total or in part, at the request of other institutions or individuals for the purpose of scholarly research.

I understand that my MRP may be electronically available to the public. 
All Kinds of People, All Kinds of Ways

Master of Fine Arts, 2019

Klasha Fernandes

Documentary Media

Ryerson University

\section{ABSTRACT}

This masters research project, All Kinds of People, All Kinds of Ways, proposes that gender is a constructed concept produced by colonial, capitalist, and patriarchal structures. This is illustrated through a three-channel video installation of the same name that utilizes conversations with two-spirit, Anishinaabe participants whose traditions express the fluidity of gender identity. The research done in this paper further supports these discussions through an analysis of feminist and queer theory, as well as a look at various cultures around the world that have similar understandings of non-fixed gender. 


\section{ACKNOWLEDGEMENTS}

I would like to greatly thank Cleo Keahna and Evelyn Pakinewatik for generously sharing their stories with me, and broadening my thinking in the creation of this work. I would also like to acknowledge the assistance from my supervisor Katy McCormick and my

advisor, Annie MacDonell, whose guidance allowed me to improve my art making and writing. Finally, my deepest gratitude goes to Savina Edward for her endless support throughout this process. 
TABLE OF CONTENTS

$\begin{array}{lr}\text { Introduction } & 1\end{array}$

Chapter 1: Context 2

Nature vs. Nurture $\quad \mathbf{4}$

Propagation of Gender Binaries $\quad 6$

The Effects of Colonization 13

$\begin{array}{lr}\text { Chapter 2: Methodology } & \mathbf{2 1}\end{array}$

$\begin{array}{ll}\text { Motivation } & \mathbf{2 1}\end{array}$

Initial Trajectory of the Project

Finding Participants $\quad 25$

Content Research $\quad 27$

Question List $\quad \mathbf{2 9}$

Visuals Leading to an Installation $\quad \mathbf{3 0}$

The Installation as Realized at Beaver Hall Gallery 32

Chapter 3: Documentary Relevance $\quad 38$

$\begin{array}{ll}\text { Conclusion } & 43\end{array}$

Bibliography $\quad 44$ 


\section{INTRODUCTION}

My project entitled All Kinds of People, All Kinds of Ways utilizes conversations with Indigenous two-spirit people, ${ }^{1}$ in order to reveal the fluidity of gender, as it has been uniquely understood through time and space. This essay takes evidence from gender and feminist theorists, as well as various cultures and traditions that have historically conceived of gender in complex ways, in order to counter the commonly accepted notions of gender binaries. The three-channel video installation presents the ways in which gender is informed and reinforced through language, capitalism, and colonialism. By utilizing interviews with participants Cleo Keahna and Evelyn Pakinewatik, one is able to see how Anishinaabe teachings position gender as something deeply rooted in spirituality. As a result, gender is understood to be constantly in flux, and thus, irreducible to simply "masculinity" or "femininity" as they are proposed by Western heteronormative ideology. Through these conversations the discourse is broadened to a more holistic understanding of gender, sex, and sexuality, while attempting to dismantle seemingly inescapable gender structures to which we are often exposed. Through the entry point of two-spirit identity, Evelyn and Cleo share their deep cultural and spiritual traditions that have long understood the need for human connection beyond the limitations of male and female, while necessarily acknowledging intersections of race, culture, class, and age.

\footnotetext{
${ }^{1}$ According to the LGBTQ2S+ Health the term "two-spirit" refers to a person who identifies as having both a masculine and feminine spirit, and is used by some indigenous people to describe their sexual, and/or spiritual identity. "Two-Spirit Community," Re:searching for LGBTQ2S+ Health, accessed August 19, 2019, https://lgbtqhealth.ca/community/two-spirit.php Two-spirit identity is further discussed from pgs. 18-22.
} 


\section{CONTEXT}

\section{Nature Vs. Nurture Debate}

Gender, sex, and sexuality are complicated concepts that are incredibly difficult to pin down, and yet particular societies deem that finite lines need to exist within and between each category. Sex refers to the physical and physiological features that categorize individuals into males and females (e.g. a penis as an indicator for males, versus a vagina as an indicator for females). Gender refers to the cultural characteristics and norms associated with being male or female. Finally, sexuality refers to a person's sexual attraction to a particular sex. ${ }^{2}$ These distinctions and the conversations surrounding them are relatively recent, but have been rooted largely in ongoing debates regarding nature versus nurture. This deliberation primarily argues that the essence of human existence is influenced either by biological determinism or social construction. Biological determinism argues that "the accepted cultural perspective on gender views women and men as naturally and unequivocally defined categories of being with distinctive psychological and behavioural propensities that can be predicted from their reproductive functions." ${ }^{3}$ Through this line of thinking all human aspects are predetermined by biological factors and therefore "natural," and those people that do not fall into a prescribed category are often pathologized and diagnosed with a clinical syndrome. "The obvious problem with this is that "male" and "female" become

\footnotetext{
${ }^{2}$ William Little, "Gender, Sex, and Sexuality," in Introduction to Sociology, (Houston: Rice University Press, 2016), 367.

${ }^{3}$ Candace West and Don H. Zimmerman, “Doing Gender," Gender and Society 1, no. 2 (1987): 128, http://www.jstor.org/stable/189945.

4 lbid., 145.
} 
normalized categories and those that stand outside those binaries are deviant and in need of treatment.

In opposition to this is the theory that both sex and gender are socially constructed. This school of thought developed through decades of feminist theory, as well as anthropological and sociological research. The development began in the 1970 s when radical, liberal, and cultural feminists began to make links between culture and the formation of gender. ${ }^{5}$ Since then, these theories, taken up by post-structural feminists, have led to an expansion of the concept of identity that has often been taken for granted. ${ }^{6}$ Thus, they deem that human behavior is influenced by one's environment and social settings, arguing that traditionally prescribed roles of men and women, in Western thinking, are a consequence of patriarchal society. ${ }^{7}$ While biological determinism insists that these traits and roles are rooted in the ingrained anatomy and neurology of males and females, social constructivism argues that the very idea of male and female needs to be called into question as "our human nature gives us the ability to learn to produce and recognize masculine and feminine gender displays." 8

Most feminist critiques take into consideration the problematics of patriarchal society, and there is already a clear perception that there exist socially constructed gender differences, which is evident:

\footnotetext{
${ }^{5}$ Mary Bucholtz, "The Feminist Foundations of Language, Gender, and Sexuality Research," in The Handbook of Language, Gender, and Sexuality, 2nd Edition, eds. Susan Ehrlich, Miriam Meyerhoff, and Janet Holmes (New York: Wiley Blackwell, 2014), 24.

${ }^{6}$ Bonnie Mcelhinny, "Theorizing Gender in Sociolinguistics and Linguistic Anthropology," in The Handbook of Language and Gender, eds. Janet Holmes and Miriam Meyerhoff (New York: Wiley Blackwell, 2003 ), 25.

7 Terrell Carver, "Gender" in Political Concepts, ed. Richard Bellamy, and Andrew Mason (Manchester: Manchester University Press, 2003), 172.

${ }^{8}$ West and Zimmerman, “Doing Gender," 130.
} 
In the division of labour into paid and unpaid work, in the sexual segregation of workplaces and the creation of "men's" and "women's" work, in differences in wages, and in discrimination in job training and promotion. Gender differences are created in bureaucratic interactions in legal, medical, psychiatric, and welfare settings. ${ }^{9}$

Which is to say that feminism in North America centrally situates these inequalities faced by women, explaining them to be a result of hegemonic structures imposed by men.

While these arguments are very important and necessary to make strides for women, "the vast majority of recent research is grounded in contemporary theories of gender and sexuality that view identities as highly variable sociocultural constructs produced in large part through language." ${ }^{10}$ Feminist theorists like Judith Butler and Gloria Anzaldúa have allowed for a more complex approach to how identity can be understood, thus, diversifying the concept of "woman." Anzaldúa looks at how gender, race, and class are all constructed identities that intersect with each other importantly drawing attention to the unique experiences felt by racialized gendered bodies. ${ }^{11}$ This is imperative to opposing an essentialized idea of white, middle-class women, who often stood at the center of feminism in the past. In this way the label of "woman" is questioned because there are no universal identifiers that make up this culturally created identity. Butler similarly interrogates the construction of identity, explaining that:

\footnotetext{
${ }^{9}$ Mcelhinny, "Theorizing Gender in Sociolinguistics and Linguistic Anthropology," 32.

${ }^{10}$ Bucholtz, "The Feminist Foundations of Language, Gender, and Sexuality Research," 36.

${ }^{11}$ Mary Bucholtz, "Bad Examples: Transgression and Progress in Language and Gender Studies," in Reinventing Identities: The Gendered Self in Discourse, eds. Mary Bucholtz, A.C. Liang, and Laurel A. Sutton (Oxford: Oxford University Press, 1999), 5.
} 
To be a woman is to have become a woman, to compel the body to conform to an historical idea of "woman," to induce the body to become a cultural sign, to materialize oneself to obedience to an historically delimited possibility, and to do this as a sustained and repeated corporeal project. ${ }^{12}$

Butler suggests that the concept of gender is entirely constructed, and the notion of womanhood and female identity is one that has been fabricated over time, developing and updating the signifiers that mark "femaleness." These signifiers are repeated over and over again by all bodies that are labeled as "woman" in order to uphold its legitimacy. In her text Gender Trouble Butler developed the idea of performativity in regards to gender, explaining that gender is in fact a performance that is vastly informed by our surroundings and upbringing. On the performativity of gender Butler explains, "what we take to be an internal essence of gender is manufactured through a sustained set of acts, posited through the gendered stylization of the body."13 Which is to say that certain gestures, bodily acts, and modes of thinking become deeply internalized through repetition and reinforcement; thus we perform maleness or femaleness on a regular basis through the cultural and historical influences imposed upon us. If gender is then perceived as performative in all its gestures and acts, its use of linguistics and psychology, it thus means that there is no identity to begin with. Gender does not exist. These traits and characteristics are not predetermined or informed by any biological composition; they are developed over time through interaction, reinforcement, and sustained social performance. This leads to an internalized perception of "self" which

\footnotetext{
12 Judith Butler, "Performative Acts and Gender Constitution," in The Feminism and Visual Culture Reader Second edition, ed. Amelia Jones (New York: Routledge, 2010), 484.

${ }^{13}$ Judith Butler, Gender Trouble: Feminism and the Subversion of Identity, (New York: Routledge, 1990), 12.
} 
too is informed by external influence and is subsequently regulated and policed in order to conform to "normalcy." 14

\section{Propagation Of Gender Binaries}

It becomes evident, particularly in the West, that the categories of male and female are considered to be necessary to the functionality of society and thus require individuals to fulfill one identity or the other. ${ }^{15}$ "While it is individuals who do gender, the enterprise is fundamentally interactional and institutional in character, for accountability is a feature of social relationships and its idiom is drawn from the institutional arena in which those relationships are enacted." ${ }^{16}$ Our immediate inclination to perform masculinity or femininity is policed by larger institutions, each other, and ourselves. Interestingly, the genitalia that supposedly insights "maleness" or "femaleness" usually remains unseen in public, however, there is still a need to perform the traits associated with the sex organ in an external way. A social contract is implicitly established where each individual relies on the other to uphold an accepted and accurate presentation of men and women. We are conditioned to do so through repetition and discipline. "Where people's behaviour does not conform to dominant norms of masculinity or femininity, it is rendered unintelligible or incoherent: certain people or certain behaviours may not be recognized as legitimately human."17 Through

\footnotetext{
${ }^{14}$ Butler, "Performative Acts and Gender Constitution," 489.

${ }^{15}$ Lee M. Kochems and Sue-Ellen Jacobs, "Gender Statuses, Gender Features, and Gender/ Sex Categories: New Perspectives on an Old Paradigm" in Two-spirit People: Native American Gender Identity, Sexuality, and Spirituality, eds. Sue-Ellen Jacobs, Wesley Thomas, Sabine Lang (Chicago: University of Illinois Press, 1997), 258.

${ }^{16}$ West and Zimmerman, “Doing Gender," 136-137.

17 Mcelhinny, "Theorizing Gender in Sociolinguistics and Linguistic Anthropology," 24.
} 
history and in contemporary politics it is apparent that those who do not adhere to the heteronormative modes of gender, sex, and/or sexuality become targets of persecution, violence, or punishment. This fact alone, that there must be a policing of gender conformity, suggests that there is some collective understanding that gender is indeed constructed and accomplished, or else there would be no need to enforce compliance. ${ }^{18}$

“Culture, academia, medicine, society, perceived as 'objective' is merely the subjective perception of men." ${ }^{19}$ Male biases are taken as objectives for every field and more broadly society; our modes of existence that are argued as natural, innate, biological, or necessary are in fact dictated by patriarchy. The male control of "culture, religion, language and knowledge" has led to the internalization of white patriarchy in most individuals and male violence towards female and queer bodies, and particularly in the West, to racialized bodies as well. ${ }^{20}$ The adherence to gendered categories is a structure upheld in levels of government, religious sectors, and academic institutions, in which patriarchy continues to prevail and hold power. Thus, breaking away from or problematizing gender is incredibly difficult because it means defacing the authority of male power held for centuries.

The adoption of gendered identities happens at every level of life starting with pregnancy, when parents often yearn to know the sex of their child, leading to preplanning their children's future in accordance with their ascribed sex and subsequently coding them into pink or blue. There is a cyclical form of child rearing, in

\footnotetext{
18 Butler, "Performative Acts and Gender Constitution," 489.

${ }^{19}$ Valerie Bryson, "Radical Feminism: Knowledge, Language and Patriarchy," in Feminist Political Theory, (1992), 222, doi: https://doi.org/10.1007/978-1-349-22284-1_13.

${ }^{20}$ Ibid., 222.
} 
which parents pass on their learned modes of gendered performance ensuring that their children too develop "appropriately" within their given genders. Thus, parents "[apply] socialization mechanisms to refine the behaviour of males and females along dimensions of difference that are culturally approved and parentally preferred." ${ }^{21}$

As previously discussed, the institution of Western medicine has a history of pathologizing individuals that do not fit such binaries; in hospitalized births sex becomes essential to the individuals' identity formulation. ${ }^{22}$ Babies that exhibit any signs of being intersex are forced to have surgery or take hormonal medication to "normalize" their physiology to suit either maleness or femaleness, at times with parental support and at other times without informed consent. ${ }^{23}$

In the case of intersex and transsexual individuals "[they] make visible what culture has made invisible - the accomplishment of gender" ${ }^{24}$ Transgender and transsexual people are born with particular genitalia that biological determinism suggests would lead to naturally occurring characteristics that coincide with their reproductive organs. However, they defy these circumstances regularly by "analyz[ing] and figure[ing] out how to act within socially structured circumstances and conceptions of femininity [or masculinity] that [people] born with appropriate biological credentials come to take for granted early on."25 Many trans people accomplish gender by altering

\footnotetext{
21 J. Richard Udry, "Biological Limits of Gender Construction," American Sociological Review 65, no. 3 (2000): 443.

${ }^{22}$ Kochems and Jacobs, "Gender Statuses, Gender Features, and Gender/ Sex Categories: New Perspectives on an Old Paradigm," 259.

${ }^{23}$ World Health Organization, Eliminating forced, coercive, and otherwise involuntary sterilization, (Geneva: World Health Organization, 2014), 2.

${ }^{24}$ West and Zimmerman, “Doing Gender," 131.

${ }^{25}$ Ibid., 131.
} 
their performances in order to pass as acceptably male or female in the world, learning the conventional models of gender presentation that are not "innately known" to them as a result of their sex organ. The pressure to affectively execute this performance can be incredibly high because any discrepancy in the enactment can lead to marginalization, incarceration, and violence.

Even if parents decide to raise their children without gender expectations there are many challenges to maintaining a life removed of gendered coding. Once enrolled in school, children find it incredibly difficult to develop an identity detached from masculinization or feminization when faced with teachers that encourage this behavior and peers who have learned similar conduct as well. ${ }^{26}$

In a study done by Marjorie Faulstich Orellana on classroom writing workshops attended by Latin American, primary school children from working class families, the social construction of identity becomes triply informed by race, gender, and class. The workshop allowed for male and female students to write their own creative short stories, subsequently sharing them with the class. ${ }^{27}$ Orellana found that "the students did not voluntarily cross gendered borders in their writing...generally inscrib[ing] their characters within supposedly gender-appropriate roles," ${ }^{28}$ characters were distinctly male or female and most students found difficulty in imagining a fluidity of roles

\footnotetext{
${ }^{26}$ Rebecca Bigler, Amy Roberson Hayes, and Veronica Hamilton, "The Role of Schools in the Early Socialization of Gender Differences," Encyclopedia on Early Childhood Development online, last modified August, 2014, http://www.child-encyclopedia.com/gender-early-socialization/according-experts/roleschools-early-socialization-gender-differences.

27 Marjorie Faulstich Orellana, "Good Guys and "Bad" Girls: Identity Construction by Latina and Latino Student Writers," in Reinventing Identities: The Gendered Self in Discourse, eds. Mary Bucholtz, A.C. Liang, and Laurel A. Sutton (Oxford: Oxford University Press, 1999), 64.

28 Ibid., 79.
} 
between genders. Children pick up these designated fixtures on gendered identity that are fairly quickly learned from surrounding sources. In addition, the students being from low-income households often internalized a notion that hard work and intelligence could lead to wealth. Orellana cautions that there is a danger in romanticizing all forms of subversion as liberatory. ${ }^{29}$ In other instances, children subverted racial stereotyping by having their Latino or Latina characters in heroic roles, while others centrally featured blonde-haired and blue-eyed characters, despite all students in the class having dark hair and dark eyes. ${ }^{30}$ In regards to race and class, for the children there seems to be an apparent hope for an alternative identity that follows hegemonic structures. While this was not synonymous with all the students for those that did pursue alternative identities it appears as though the stories were a mode for the children to embody identities that they have often seen and perceive as valuable. The white, middle-class hero continues to permeate media and society in North America, and has resulted in a construction of images that are bound up with dominant racial discourses. " 31 Race, gender, and the visual structure one another in a complex set of interlocking, epistemological feedback loops." ${ }^{32}$ These categories of identity become nearly inseparable and the formation of identities are both learned and informed by visual culture. In regards to Orellana's research, storytelling for the children became an opportunity to rewrite the stories enforced upon them and rethink in part the

\footnotetext{
${ }^{29}$ Faulstich Orellana, Marjorie, "Good Guys and "Bad" Girls: Identity Construction by Latina and Latino Student Writers," 79.

30 Ibid., 72.

31 lbid., 70.

32 Judith Wilson, "One Way or Another: Black Feminist Visual Theory," in The Feminism and Visual Culture Reader Second edition, ed. Amelia Jones (New York: Routledge, 2010), 20.
} 
limitations of their identities. The fictional aspect of the medium perhaps allowed for the capacity to think beyond a culturally and socially restricted world, however, the boundless possibility of fiction is still evidently limited by the heteronormative and hegemonic structures that infiltrate our societies.

Consumer culture, the media, and language are inundated with male and female categorization. Advertisers in particular market products in specified ways to men and women; this has been a point of research by feminists for decades, understanding that consumerism is widely dictated by gender. In the 1970 s it became evident to feminist movements that advertising in the United States and Europe used women's bodies to sell everything, and that the type of representation sexualized and objectified women. ${ }^{33}$ "Within a capitalist structure all work is assigned 'value' and that women's primary use/value is sexual, in the house, and/or relatively lower paid office work." ${ }^{34}$ These practices both reinforce and influence modes of gendered behaviour. As posited by social learning theory, people often identify themselves with others in commercials and other visual channels that appear as they do and as a result they learn, imitate, and internalize behaviour observed in the media. ${ }^{35}$ Once again this phenomenon is multilayered when the viewer is racialized or socially stratified. In the case of black women they have had to compete with and formulate their own identities upon a mass of stereotypes and tropes. As Judith Wilson states, "the combined stigma of pre- and post-

\footnotetext{
33 Katherine Toland Frith and Barbara Mueller, Advertising and Societies: Global Issues, (New York: Peter Lang Publishing, 2010), 94.

34 Ibid., 97.

${ }^{35}$ Susan Lynn, Kristie Walsdorf, Marie Hardin, and Brent Hardin, "Selling Girls Short: Advertising and Gender Images in Sports Illustrated for Kids," Women in Sport \& Physical Activity Journal 11, no. 2 (2002): 78.
} 
emancipation economic and sexual servitude ... visual production and reproduction takes us well beyond preoccupations with the Hottentot Venus and Josephine Baker." ${ }^{236}$ The historical objectification and oversexualization of the black female body has continued to saturate and homogenize black female identity, which continues to be contested by black feminists. ${ }^{37}$ Identity, in all its forms, is constantly mediated by colonial structures that enforce categorized expressions of self, creating and administering the boundaries and limitations felt by racialized, and gendered bodies. In addition to the profound problems brought about by consumer culture and capitalism, language solidifies a system founded on categorization. "Speech is the central way we come to know ourselves, reveal ourselves to others, and express our own identities ... for individuals to repress such speech (the speech of desire) in themselves ... is to impoverish possibilities for transformative human discourse."38 Similar to visual media, if we are limited by the very words we are given how can we hope to express our desires or ourselves, and grow in any meaningful way? The English language based in Latin prescribes gendered labels to a variety of fields, having been formed under patriarchy. It demands an indication of one's gender and sex through the use of "he" and "she." The terms "female" and "male" are used as normative functions of language and hence form a social construction, which insists that the only mode of being exists in binaries. ${ }^{39}$ In her text Man-Made Language Dale Spender explains that "[language] is not a neutral medium of communication, but involves a way of structuring

\footnotetext{
${ }^{36}$ Wilson, "One Way or Another: Black Feminist Visual Theory," 21.

37 Ibid., 21.

38 Jean Bethke Elshtain, "Feminist Discourse and Its Discontents: Language, Power, and Meaning," in Signs 7, no. 3 (1982): 608, https://www.jstor.org/stable/3173857.

${ }^{39}$ Butler, Gender Trouble, 15.
} 
our thought that is based on men's perceptions." ${ }^{\prime 40}$ Other radical feminists like Sheila Rowbotham also argue that "The language of theory - removed language - only expresses a reality experienced by the oppressors. It speaks only for their world, from their point of view [...] Language is part of the political and ideological power of rulers." ${ }^{41}$ The English language is the language spoken most broadly, developed and spread through colonial and religious means. The continued hegemonic power possessed by the West ensures its continued use in places of power often propagating patriarchal, colonial, and capitalistic notions of normativity, ensuring hegemonic power by debasing bodies, societies, and languages deemed as Other. The rhetoric, language, and discourse found in various institutions, "simultaneously sustain, reproduce, and render legitimate the institutional arrangements" that reinforce gender categories. ${ }^{42}$ Language strongly reinforces these deeply embedded beliefs of binarism in large part by limiting the words we are able to use to describe unique and complex experiences. If we are unable to formulate words to express complex feelings and identities, then in turn these, feeling and identities become reduced to simplistic thoughts mediated by permitted and limiting words.

\section{The Effects of Colonization}

The languages and traditions of peoples from many cultures around the world complicate the normalized gender expectations propagated by the West. Through

\footnotetext{
40 Bryson, "Radical Feminism: Knowledge, Language and Patriarchy," 223.

41 Sheila Rowbotham, Woman's Consciousness, Man's World (Baltimore: Penguin Books, 1973), 32-33. Found in Elshtain, "Feminist Discourse and Its Discontents: Language, Power, and Meaning," 604.

${ }^{42}$ West and Zimmerman, "Doing Gender," 146.
} 
colonization these notions of pathologized gender, language categorization, and the binaries of gender and sex have been enforced upon multiple populations that have understood gender completely differently to the ways Western societies have developed under patriarchal schemes.

One such example is the māhū people of Hawaii. The māhū were individuals with male genitalia who were either transgender or gravitated towards effeminate physical presentation, but embodied both genders. ${ }^{43}$ They were often considered to be a third gender, and took up traditional spiritual and social roles within Hawaiian culture. ${ }^{44}$ Precolonially, māhū were respected as teachers and keepers of cultural traditions and genealogies. ${ }^{45}$ In the $19^{\text {th }}$ century under Euro-American domination and Christian conversion, policing sexuality became a primary concern. Thus, laws were enforced to criminalize "sexual practices that had hitherto been legally and socially acceptable." This led to the stigmatization and persecution of māhū individuals; in fact, "māhū" is now a derogatory term used against gay and trans people. ${ }^{47}$ The once accepted and regarded role of the māhū was lost because it marked a state of being that was different in both gender and race unable to fit the ideologies enforced by Western colonization.

Much like the history of the māhū once found in pre-colonial Hawaii, the hijra are a community of individuals that have been a part of Indian history for centuries. "For

\footnotetext{
${ }^{43}$ Geoff Alexander, America Goes Hawaiian: The Influence of Pacific Island Culture on the Mainland (North Carolina: McFarland \& Company Inc., 2019), 53.

${ }^{44}$ Ibid., 55.

${ }^{45}$ Andrew Matzner, “'Transgender, queens, mahu, whatever': An Oral History from Hawai'l," in Intersections: Gender, History and Culture in the Asian Context, no. 6 (2001): 7.

${ }^{46}$ Aleardo Zanghellini, "Sodomy Laws and Gender Variance in Tahiti and Hawai'i," in Laws 2, no. 2 (2013): 58.

${ }^{47}$ Ibid., 51.
} 
the most part, hijras are phenotypic men who wear female clothing, ${ }^{48}$ but they also multiply the notion of gender beyond a third gender or any gendered or sexed classification as they do not perceive to exist between the categories of male or female at all. ${ }^{49}$ Under the colonization of Victorian England constructions of crime and deviance were made to build a "criminal caste." ${ }^{50}$ The Criminal Tribes Act outlawed hijra communities and any labour they performed. Hijra bodies were surveyed and removed of any legitimate heritage by confiscating their status and lands, originally granted to them by royal decree. ${ }^{51}$ There were many hijra communities across India that had existed for centuries, and had been an integral part of religious and cultural customs. Now, however, hijras and all other non-heterosexual or cisgendered forms of identity have been criminalized and stigmatized. ${ }^{52}$

Found in Indonesia are the Bugis who are a large ethnic group in South Sulawesi, and have for centuries understood gender as existing on a spectrum. "Their language offers five terms referencing various combinations of sex, gender, and sexuality: makkunrai ('female women'), oroani ('male men'), calalai ('female men'), calabai ('male women'), and bissu ('transgender priests'). These definitions are not exact, but suffice." ${ }^{53}$ For the Bugis community people do not exist within two discrete sexes, rather everyone lies on a spectrum displaying various characteristics of "masculinity" and

\footnotetext{
${ }^{48}$ Gayatri Reddy, With Respect to Sex: Negotiating Hijra Identity in South Asia (Chicago: University of Chicago Press, 2010), 4.

${ }^{49}$ Ibid., 4.

${ }^{50}$ Ibid., 27.

${ }^{51}$ Ibid., 27.

${ }^{52}$ Ibid., 20.

53 Sharyn Graham Davies, "What we can learn from an Indonesian ethnicity that recognizes five genders," The Conversation, last modified June 16, 2016, https://theconversation.com/what-we-can-learn-from-anindonesian-ethnicity-that-recognizes-five-genders-60775.
} 
"femininity." ${ }^{54}$ In their society they hold a strong belief that all five genders must coexist harmoniously, however, this ideology has changed drastically and there has been increased harassment and discrimination of peoples with nuanced and alternative understandings of gender, sex, and sexuality. ${ }^{55}$

In addition to these cultures that recognize gender variability and a lack of binaries, these notions of fluidity have also been evident in the muxe from Mexico, the burrnesha from Albania, the köçek from Turkey, the mashoga from Kenya, among others. ${ }^{56}$ All of these peoples have existed through history taking up their own roles in their respective societies, being accepted and valued much like two-spirit peoples among the Indigenous peoples of North America.

Moreover, it is important to note that "two-spirit" is an umbrella term coined in 1990, which was adopted by contemporary Indigenous peoples for dialogue between tribes about gender fluidity. ${ }^{57}$ Two-spirit cannot be literally translated into any Indigenous language, and is also not a label taken up by all Indigenous peoples. In regard to Indigenous conceptions of gender identity Sabine Lang states:

Cultural constructions of gender and gender roles varied, and still vary, widely in Native American cultures given the diversity among these cultures. Regardless of specific differences in the construction of gender and gender roles, a majority of

\footnotetext{
${ }^{54}$ Sharyn Graham Davies, "What we can learn from an Indonesian ethnicity that recognizes five genders," The Conversation.

${ }^{55}$ Farid M. Ibrahim, “Homophobia and rising Islamic intolerance push Indonesia's intersex bissu priests to the brink," Australian Broadcasting Corporation News, last accessed February 26, 2019, https://www.abc.net.au/news/2019-02-27/indonesia-fifth-gender-might-soon-disappear/10846570.

56 "A Map of Gender-Diverse Cultures," PBS online, last modified August 11, 2015, http://www.pbs.org/independentlens/content/two-spirits_map-html/.

57 Sabine Lang, "Various Kinds of Two-Spirit People: Gender Variance and Homosexuality in Native American Communities," in Two-spirit People: Native American Gender Identity, Sexuality, and Spirituality, ed. Sue-Ellen Jacobs, Wesley Thomas, Sabine Lang (Chicago: University of Illinois Press, 1997), 100.
} 
Native American cultures define gender in a way that allows for the cultural construction of more than two genders. ${ }^{58}$

Indigenous practice and ideology of sexual and gendered difference has existed for centuries, with stories orally passed down about many "two-spirit" heroes from the past. These individuals were a part of the community like any other citizen; they participated in their own roles, occupying positions of honour and communal value. ${ }^{59}$ The Vengeful Wife and Other Blackfoot Stories, a text by Hugh Dempsey, is a collection of stories of past Native peoples whose remarkable lives as two-spirit individuals were orally passed down through generations. ${ }^{60}$ Indigenous ways of living taken up by certain tribes have often involved communal methods of sharing and support, often through an engagement with the land and spirits. Dempsey's text explains that Blackfoot culture from Northern Montana and Southern Alberta had various terms to indicate the spectrum of gender difference including piegan man, pikunikwan, and pikunaki, which indicated the difference between individuals' gendered characteristics and sex, as well as sexual orientation. ${ }^{61}$ One particular story talks about a man named Four Bears who lived from around 1830 to 1883 . On a spiritual journey through the Rocky Mountains, Four Bears was told by the Sun spirit to dress as a woman. Four Bears became an A'yai-kik-ashi, a man who "acts like a woman." He wore women's clothing for religious activities and going to war; he was often seen as a

\footnotetext{
58 Lang, "Various Kinds of Two-Spirit People: Gender Variance and Homosexuality in Native American Communities,"103.

${ }^{59}$ Micelle Cameron, "Two-Spirited Aboriginal People: Continuing Cultural Appropriation by Non-Aboriginal Society," Canadian Woman Studies 24, no. 2 (2005): 124.

${ }^{60}$ Hugh A. Dempsey, The Vengeful Wife and Other Blackfoot Stories (Norman: University of Oklahoma Press, 2014), 48.

61 Ibid., 48.
} 
prophet. $^{62}$ This is evidence that the spectrum of fluidity was considered sacred to Indigenous peoples; these were identities given to them by the spirits and therefore normalized within their society.

The Navajo use terms for gender non-conformity including, nádleehi, asdzáán, and dilbaa, which are all understood to be fluid terms and cannot be described within gender binaries. 63 "In Navajo tradition, there is no concept of gender dysphoria; rather...there is a concept of gender diversity." ${ }^{64}$ Gender non-conforming people are recognized by elders and family in their community at a young age, and express their gender differently from day to day. ${ }^{65}$ The lack of acknowledgement of gender dysphoria in Navajo tradition is significant because in the West "dysphoria" is used to comprehend gender diversity, implicating the degree to which it is pathologized. It suggests that there is a normative way of feeling and being, and that gender diverse people experience a dysfunction that contradicts this "normal" state. The term is again an example of the limitations of Western science and language deeming any difference as problematic. The unfortunate solution in the West is to enforce categorization, rather than to break molds to accept all kinds of experiences.

The consequences of colonization and Western settlement have deeply affected Indigenous communities across North America today. Among the profound loses in tradition, culture, language, land, community, and identity were also these core

\footnotetext{
62 Dempsey, The Vengeful Wife and Other Blackfoot Stories, 48.

${ }^{63}$ Gabriel S. Estrada, "Two Spirits, Nádleeh, and LGBTQ2 Navajo Gaze," American Indian Culture and Research Journal 35: no. 4 (2011): 171.

${ }^{64}$ Wesley Thomas, "Navajo Cultural Constructions of Gender and Sexuality," in Two-spirit People: Native American Gender Identity, Sexuality, and Spirituality, ed. Sue-Ellen Jacobs, Wesley Thomas, Sabine Lang (Chicago: University of Illinois Press, 1997), 160.

65 Ibid., 160.
} 
understandings of gender, sex and sexuality. "The religious dogma of the Residential Schools have erased a proud and rich history of two-spirit people in most Aboriginal communities." ${ }^{66}$ This erasure has led to generations of Indigenous peoples growing up without a concept of what it means to be two-spirit, knowledge that otherwise would have been passed down by Elders. ${ }^{67}$

The contemporary terms used in North America such as transgender, gay, lesbian, agender and so on are all new terms that have come up in recent years to make up for the glaring lack of gender, sex, and sexual complexity in the English language. The terms are hugely helpful to many finally creating identities to express the complex experiences that non-binary individuals feel, however, within contemporary gender politics the terms developed are often descriptors that do not always hold value to these complexities. As my subject Cleo puts it, these terms are simply Latin-based labels and though there is value in claiming alternative identities, these terms become fabricated as a cover up rather than an interrogation of the issue within colonial and capitalistic societies. ${ }^{68}$ For many Indigenous peoples these terms do not adequately represent the reality of their experiences because "two-spirit" is an encompassing term and the particular words of each tribe denote something far greater than the specificity of the English words created today. ${ }^{69}$ Two-spirit implies one's unique understanding of

\footnotetext{
${ }^{66}$ Gil Lerat, Two-Spirit Youth Speak Out! Analysis of the Needs Assessment Tool. Vancouver, Urban Native Youth, 2004. Found in Cameron, "Two-Spirited Aboriginal People: Continuing Cultural Appropriation by Non-Aboriginal Society," 124.

67 Ibid., 124.

${ }^{68}$ Cleo Keahna, interview by Klasha Fernandes, August 3, 2018, interview, video.

${ }^{69}$ Evelyn Pakinewatik, interview by Klasha Fernandes, August 10, 2018, interview, video.
} 
their gender as it relates to their spirit, their heritage, and their own understanding as well as their community's understanding of their identity.

Within Western culture itself the perceptions of masculinity and femininity have shifted. "300 years ago European men of power and means sought to appear gorgeous by wearing wigs, facial powder and beauty marks, leg-accentuating stockings, high heels, velvet robes, and furs." ${ }^{\prime 70}$ Which is to say that gender has clearly shifted through history as simply another aspect of culture. Given the fact that so many cultures across the world and at different times understood that gender functioned beyond two categories makes it evident that there is certainly more to humans than a binarized form of sex, sexuality, and gender. For the aforementioned tribes, communities, and populations outside the Western world there has been a spiritual and cultural understanding that either all people reside on a spectrum of identity, that some exist on the plain of an alternate gender, or that some require none at all. The existence of these alternative forms of being were never points to be ostracized, ridiculed, or fixed. Only with Western colonization have these societies suffered, breaking away not only from these complex understandings of identity, but also an overall loss of communal necessity.

\footnotetext{
${ }^{70}$ Eleanor M. Miller, and Carrie Yang Costello, "The Limits of Biological Determinism." American Sociological Review 66, no. 4 (2000): 593.
} 


\section{METHODOLOGY}

\section{Motivation}

Personally, my motivation for pursuing this subject matter lies in coming to terms with my inability to conform to prescribed roles. How do we move through the world if our entire existence becomes forcibly scripted? In a perfect world one would be as genderless and fluid as humans are supposed to be; however, we cling to the safety of assigned gender, circumventing the risks of deviance. Herein lies the problem: We are unable to express our true selves due to the overwhelming pressures of culture, language, race, media, institutions, and more broadly, society.

As an Indian, gender non-conforming woman in Canada I often find myself in conflict with these politically and socially enforced perceptions of race and gender. My own learnings of gender, growing up in a Catholic, Indian household were constituted by fixed roles and spaces inhabited by women that were starkly different from those taken up by men. There was little room to contest boundaries or experiment with human complexities. The gendered diversity once a part of India, as I discussed in regards to the hijra community, was largely different than the colonized India that I know as my home.

Eventually immigrating to Canada presented a new set of obstacles often experienced in communities of colour. Your presence in North America is immediately established as Other, easily written in the colour of your skin, your accent, your name. A desire to belong and assimilate into the country prevents many racialized communities from expressing "deviance" in any other way. As a result, I find my existence in Canada to be unique as an "immigrant settler" and "colonial subject." I benefit from this land 
that is not my own, but I also move through the world as an Indian non-conforming woman affected by racism and colonial ideas imposed upon South Asians in India, and in Canada. This has always affected the way I approached this subject, knowing that gender has not always been understood in the same way in all parts of the world.

Despite my own complex subjectivity, I am well aware of the concerns present when a non-Indigenous person creates a project based on Indigenous voices. I think that it is incredibly important that Indigenous peoples have the opportunity to create their own content by and for their own communities given the fact that their voices have so often been silenced and omitted from history. However, I also do not necessarily think that stories should be limited to individual communities, as circumstantially, conversations can be broadened through inter-community dialogue. Throughout the development of this piece, ethical concerns consumed me, leading me to wonder whether or not I was in a position to be making this work, and whether I was speaking for my participants, or more broadly Anishinaabe and other Indigenous communities. I had repeatedly had these conversations with my participants, my professors, and my colleagues, trying to understand where I fit in the telling of this story that is not my own. When presenting my work on one occasion I had suggested that I learnt a great deal from my participants, and hoped that others could learn from them too. One of my professors cautioned me against this mode of thinking, explaining that there is an affinity to place marginalized peoples as educators, in order to enlighten others (usually white people) about their own racism and colonialism. This was hugely important for me in changing how I framed my project, making me question my use of linguistics and the 
way I had been approaching the topic, perhaps viewing them as ethnographic subjects and as a result, exotic Other. In discussing this with Cleo and Evelyn I found that they were hugely supportive of my work, they did not see what I was doing as a means of speaking for them, rather they saw it as creating an avenue for them to share their stories and discuss what was important to them. They described our interactions together as safe, positive, and driven by their conversations.

Having said that I think there is a huge responsibility owed as creators working on stories about marginalized communities. It is necessary that their representations, and experiences be handled consciously and with great care. To this effect, I spent a lot of time sending back interview questions, footage, and edits to my participants ensuring that they approved of what I was making. I wanted to be sure that I represented them well without falling into the stereotypical way that indigenous communities are so often presented. Indigenous representations are repeatedly centered on loss, trauma, and addiction, omitting the strength and support found in their communities that understand the importance of acceptance and familial support.

The affect of being an outsider to their community also placed me in a position to request in depth explanations of what two-spirit means because I myself did not truly know the nuances of the term. I think that this was significant because it countered central perspectives of gender rooted in capitalism and colonialism, and a gender identity that is often absent in queer discourse. Thus, these largely omitted perspectives on gender identity explained by Indigenous individuals were centrally placed, offering a more human comprehension of identity that intersects with race, spirituality, and 
community. In the end, my project still functions in part as education; this is undeniable and is an affect of requiring explanation as an outsider. My hope is that because these identities and concepts are not commonly understood, there is an opportunity for conversation about the issues beyond queer and Indigenous circles.

Importantly this project has been more than an opportunity for conversation, for me it has been a huge step in how I understand gender non-conformity, how I choose to live it, and how I have been able to internalize it in a way that certain Western queer discourse never allowed me to before.

While this piece was of great importance to me personally I did not want to place myself within the work. I am already present in the piece through the questions I asked, the visuals I captured, and the edits that I have made. To physically or aurally place myself within it would be taking away from the words shared by my participants. The point of the work was presenting a unique way of comprehending gender that is hugely lacking in the way that we currently discuss it. My views have been molded by the mainstream, and I did not want that to take up space when Evelyn and Cleo were offering alternative modes of thinking, and sharing their own personal experiences.

\section{Initial Trajectory of the Project}

When entering into the Documentary Media program I felt as though I was doing something vital in proving to people that gender and sex could not be biologically determined, but were operating within cultural and social conventions that were constantly enforced upon us. My desire, therefore, was to move beyond gender entirely, to a world that no longer had any comprehension of male or female; my 
chosen approach to my art was satire. A strategy that used irony and exaggeration to implicate institutions, and capitalism, as much as the audience who viewed the piece. I intended to create an installation that used satirical vignettes criticizing gendered advertising, fashion, parenting, and medicine, using exaggerated performance to mimic and counter the language employed when convincing people of these principles. My hope was to bring to the forefront these hegemonic structures that we have grown to accept.

After presenting this strategy on numerous occasions to faculty and colleagues early on it was apparent that I would need to bring forth documentary elements to the project either through archival footage or interviews. This is not only because the program is documentary based, but because the piece itself needed some form of reality among the performative elements. In preparation for this idea it became important to me to gather stories from other gender non-conforming people to ground the work that I was making, by presenting the individuals who were genuinely affected by these systems. I wanted the experiences shared by gender non-conforming people to offer some authenticity to the humour I was working with, and to place them at the center of the piece making it apparent to viewers that many people are affected by the imposition of binaries and conventional thought in our contemporary socio-political framework.

\section{Finding Participants}

I proceeded to look for participants by reaching out via social media groups, asking for individuals that identified as gender non-conforming, non-binary or agender who 
wanted to partake in a documentary that dismantled perceptions about the fixity of gender and sex. I also aimed to find at least seven participants who were diverse in race and age, but were situated in North America, with the intention of specifically looking at North America's comprehension of gender identity. By mid-June I was able to find four participants, and I set up Skype meetings with them to talk more about the project, my intentions, and to answer any questions that they had. After setting up relationships with each of these subjects, I was unfortunately left with only two participants due to the others' personal obstacles.

I then carried on looking for more people who were interested in the piece, and could offer something unique to my research and message. Through a chance meeting with a friend of a friend I was introduced to Evelyn. I first met Evelyn via a Skype meeting in late July and I informed them ${ }^{71}$ on why I was making the project, what I wanted to do with it and the types of questions I would be asking and we continued to have a conversations about other aspects of gender, sex, and sexuality. Evelyn explained to me that they were Anishinaabe, and identified as two-spirit, a term I recognized but about which had very little knowledge. This helped me widen the confines of my project bearing in mind questions about two-spirit identity, and the relationship between spirituality and gender, which were all ideas I had not considered prior to my conversation with Evelyn. They then told me about their friend Cleo who was also Anishinaabe and two-spirit, and would be open to participating in the documentary. Like

\footnotetext{
${ }^{71}$ Evelyn uses the pronoun "them" rather than "he" or "she" for more on personal pronouns see Mere Abrams, "What Does It Mean to Identify as Nonbinary?," Healthline, accessed August, 27, 2019, https://www.healthline.com/health/transgender/nonbinary\#takeaway.
} 
all of my other participants, I first spoke with Cleo through an initial Skype meeting, where we also talked about two-spirit identity and some of his own thoughts about the project, further developing questions about gender binaries based on our conversations. After a few more discussions with all of my participants I was pleased with the four participants I managed to get and began to prepare for the interviews.

\section{Content Research}

Prior to conducting my interviews, I had spent time reading works by gender theorists focusing on the performativity of gender, and how this was psychologically and culturally developed. As a result, they influenced a large part of the trajectory of my work, informing my argument for gender fluidity. By reading texts like Gender Trouble ${ }^{72}$ and "Gender as a Personal and Cultural Construction,"73 I developed questions surrounding the reasons for the existence of gender, why it seems necessitated by societies, the role of capitalism in this system, how gender is explicitly and implicitly encouraged, and all of the psychological influences at work. I was concerned with proving that the states of "maleness" and "femaleness" are arbitrary and entirely constructed. Making viewers aware of the particular roles and expectations that are gendered drove my motivation, including how this gendering is completely manufactured. This has remained important to me through the development of the project; however, after having those initial conversations with my participants I began

\footnotetext{
72 Judith Butler, Gender Trouble: Feminism and the Subversion of Identity, (New York: Routledge, 1990).

${ }^{73}$ Nancy J. Chodorow, "Gender as a Personal and Cultural Construction," in Signs 7, no. 3 (1995): 516-544, https://www.jstor.org/stable/3174832.
} 
to expand my line of thinking to incorporate a human element that presented how hegemony, as discussed by feminist and gender theorists, affected people living within it. Thus, I expanded my interview questions to include my participants' stories, realizing that these could be more relatable, and ground the academic theory that I had been reading.

I had conducted my four interviews from mid- to late-August at Ryerson University. It was especially important to me to begin each interview by acknowledging the land that the University was built on, given the founder, Egerton Ryerson's history as a major contributor to the residential school system. ${ }^{74} \mathrm{I}$ also made it clear to every participant that if they were uncomfortable with any questions they did not have to answer, and I would immediately shut off the camera if asked. After doing so I dove right into the questions asking them what I had developed in my list of questions, but also leaving room for them to speak as much as they wanted, share anecdotes, or talk about other things that they found to be important to the subject. Some parts of the conversations were emotional and I never pushed further if my participants did not want to speak. The most important thing during the interviews was that my participants felt safe and comfortable to share their thoughts.

In October I was able to share excerpts of the four interviews that I had collected from my four participants in class. Within the first presentation of them my colleagues and professors immediately gravitated to the conversations I had with Evelyn and Cleo,

\footnotetext{
${ }^{74}$ See Neil Semple, "Egerton Ryerson," The Canadian Encyclopedia, last modified July 27, 2017, https://www.thecanadianencyclopedia.ca/en/article/egerton-ryerson.
} 
finding their perspectives to be refreshing and largely absent in queer discourse. It was clear that the beliefs and thoughts shared by Evelyn and Cleo needed to be at the forefront of my project because they spoke about gender in vastly different ways than how gender binaries and non-conformity were discussed inside and outside of the queer community. They saw gender as something constructed but they also understood their identities, that existed beyond male and female, as a truth that was an innate part of their spirit and one that was understood and accepted by their particular community.

\section{Question List}

These were some of the questions that I asked:

- What have been your personal experiences being a gender non-conforming person [in a world that clearly requires you to be either male or female]?

- How do you choose to express your gender identity? And is there a right way or "expected" right way to be agender (an expectation within the community or from other people)?

- Can you speak about gender as a system? Why do you think it exists? Who does it serve? That kind of thing...

- $\quad$ I'm taking a more anti-capitalist approach in my project] Have you spent time thinking about gender limitations through how it functions in a capitalistic society? And can you share your thoughts on that?

- Everything, it seems, is considered in relation to male and female, do you think getting rid of those labels is the solution?

- Have you seen the agender community approach these notions through a very intersectional approach or is there still strides to be made?

- Are gender and sexuality independent or do they work in tandem with each other? (Is it necessary to consider both together?) 
- Can you speak about the relationship between spirituality and gender? (If you think there is one)

\section{Visuals Leading to an Installation}

When I began the interview process, I still intended to follow through with my initial satirical approach to the project. I was conscious of the fact that there would be a lot of visual stimulation through the various vignettes in the installation, thus I felt that the interviews needed to be executed minimally. I captured them in a traditional format that included medium shots of my participants directly facing the camera, in front of a white background.

With the changes in subject matter, however, deciding to focus on the grounding discussions offered by Evelyn and Cleo I decided that a piece with all the satirical elements I intended would simply undermine all the important content they shared. This lead me to approach the project by simplifying down to two characters, choosing to play Cleo's and Evelyn's interviews on two channels, one on each wall of a gallery space. The focus of my piece had become my participants, both the stories they shared and the thoughts they brought forward. I hoped that this strategy would centralize everything that they had to offer, and bring viewers to really focus on their words.

Through meetings with my supervisors, however, I was challenged to find ways to oppose heteronormativity in the formal aspects of my work, in order to underline and extend the complexity of my content, as well as incorporate a physical strategy that would incorporate the recurring element of fluidity in my piece. These meetings proved to be very helpful to me because it forced me to sit with the material I had gathered, and consider how to maintain focus on my participants through formal elements that 
would compliment and complicate the themes they presented. After much deliberation I settled on using fabric as a tool that could serve my message of gender fluidity, looking to artists like Hyun Jean Lee and Bill Viola to learn how they used fabric projection in their works. It took quite some time to learn the properties of optics and how light could be refracted and interplayed in order to create an experience that challenged gender conformity in the way that I hoped. 
The Installation as Realized at Beaver Hall Gallery

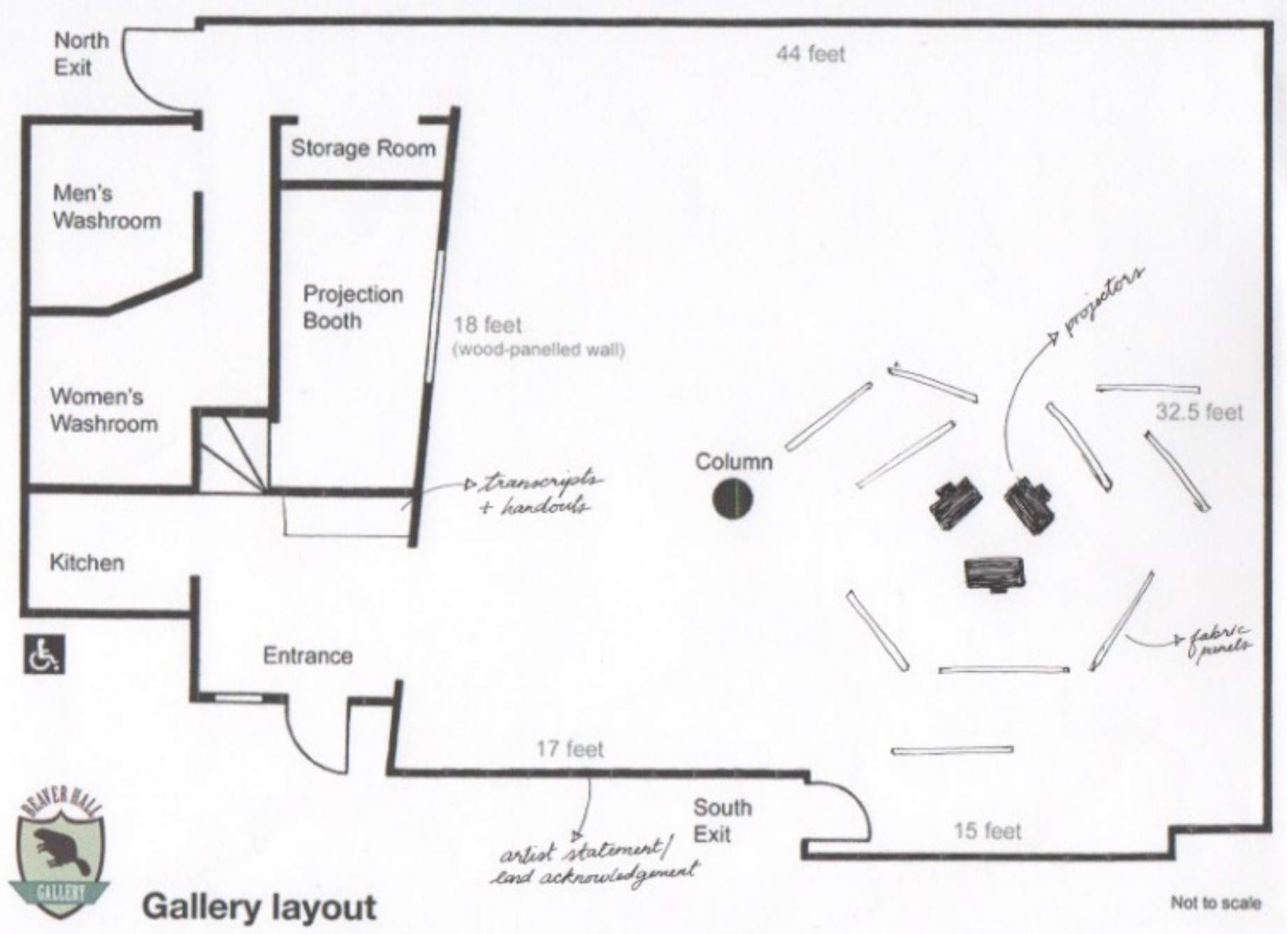

Figure 1. Floor plan of All Kinds of People, All Kinds of Ways, Beaver Hall Gallery, Toronto, 2019 


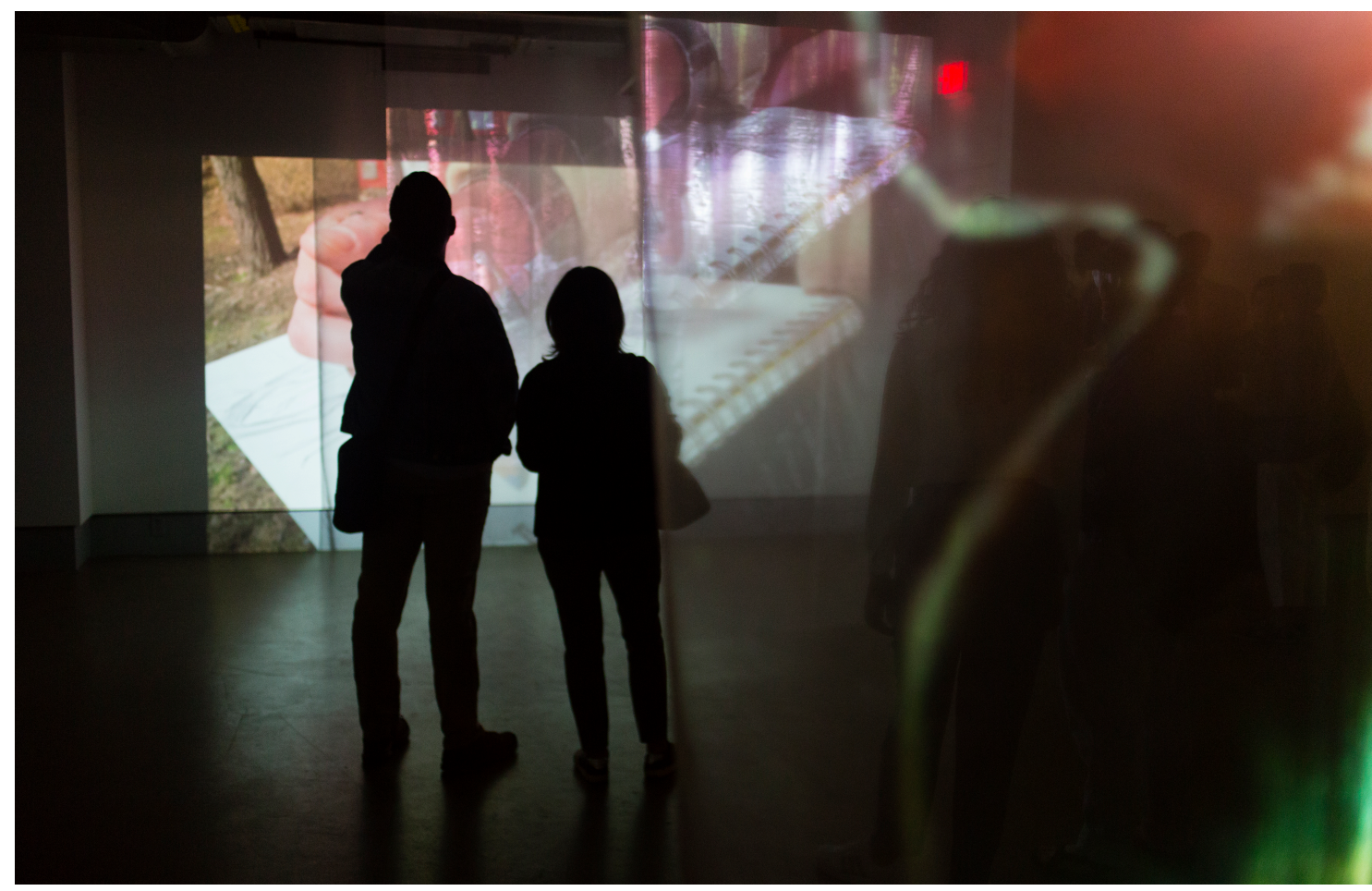

Figure 2. Installation view All Kinds of People, All Kinds of Ways, Beaver Hall Gallery, Toronto, 2019.

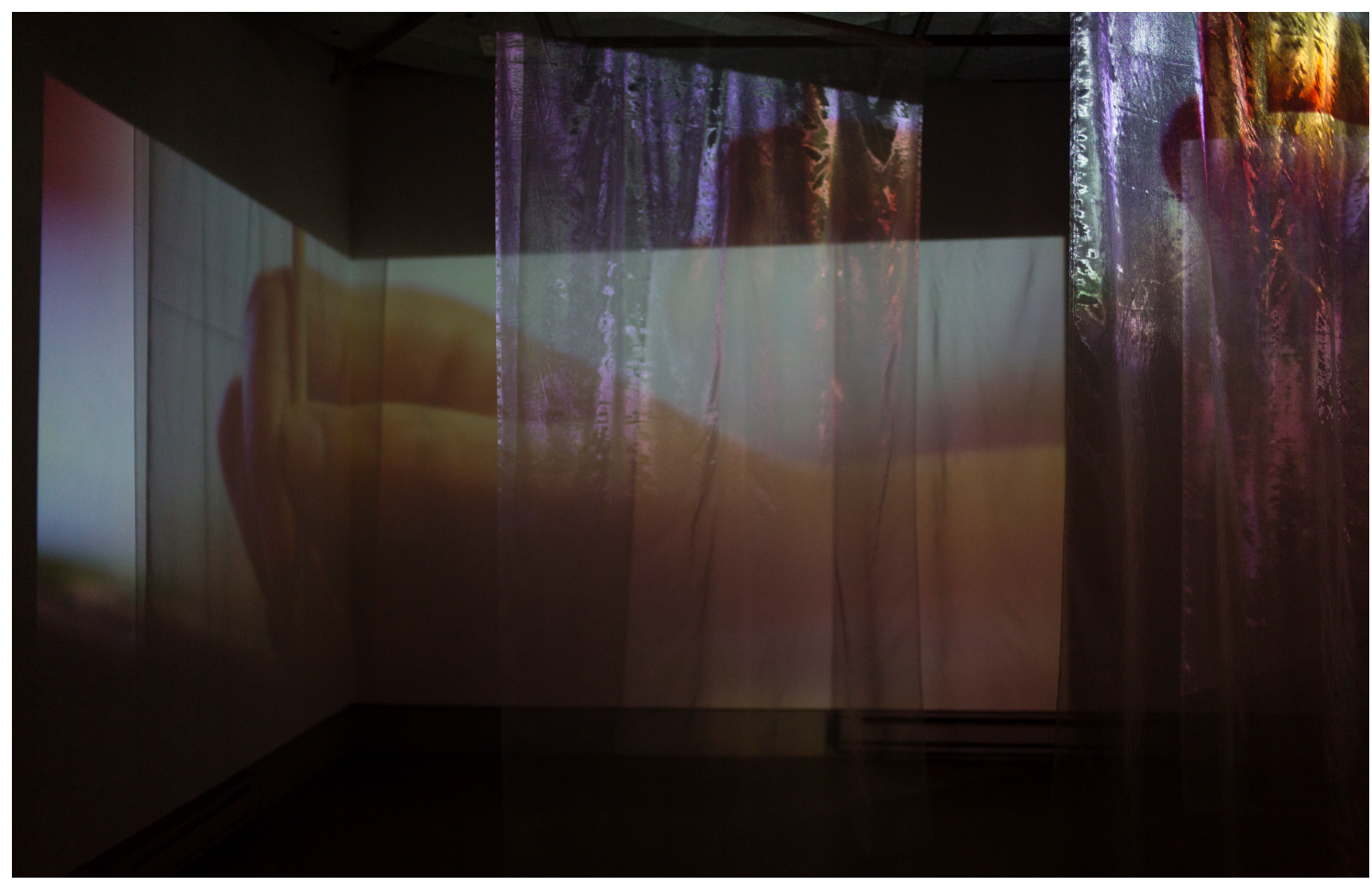

Figure 3. Installation view II, Beaver Hall Gallery, Toronto, 2019. 
In the actual installation I sought to maintain the support and enhancement of my participants' voices. As a result, I had surround-sound speakers play Evelyn and Cleo's audio throughout the gallery space, while video footage depicting close-ups of them were projected on panels of fabric hung from the ceiling. These close-ups captured Cleo's and Evelyn's eyes, hands, feet, and other features of their bodies while painting, drawing and moving through their personal spaces. These were activities chosen by them as something that represented them well. Additionally, painting and drawing can be associated with notions of building, layering and transforming much in the way that the installation itself had been constructed. In using close-ups I hoped to complicate one's perception of gender as it relates to voice, self, body, and performance. By ambiguously leaving the identity of each close-up and the speaker unknown I intended to create an opportunity to problematize presumptions made by the viewer about which participant performs which activity, thus having to grasp that gender identity is based on an internal realization rather than external presentation. Moving between interview footage, visual close-ups, and words emphasized by text, the experience progressed in a way that the audience could reflect on and process a reframing of the limiting and individualistic society we have become accustomed to. Three projectors placed at the centre of the installation projected three video channels outward onto nine pieces of fabric that rested parallel, perpendicular, and staggered to each other creating a fragmented display of the moving images. ${ }^{75}$ Three speakers were placed in the centre of the installation also pointing outward so that the

\footnotetext{
${ }^{75}$ See Figure 1.
} 
audio could be heard throughout the gallery. Panels of translucent organza allowed the videos to pass through the multiple layers of fabric, becoming fragmented by the edges of the panels and fading in appearance upon the farthest layer. The use of translucent fabric was a means to visually and physically capture notions of fluidity, ephemerality, fragmentation, and the multiplicity of identity.

The projectors, which were raised on the ceiling and pointing downwards upon the panels, allowed the footage to encompass large portions of the organza. By projecting the videos from above it also moderated the imposition of the audience's shadow as they approached the piece. The implementation of one's shadow was significant in considering our own positioning in the discussion of gender identity and implicating us in the conversation, realizing that this is not isolated to people within the queer community but is something that limits everyone. Thus, the viewer's shadow came upon the fabric when in close proximity, but did not appear as a constant presence, enabling one to focus on the piece itself without too much distraction. ${ }^{76}$ Through the three channels displayed from various areas of the gallery I hoped to make it clear that the viewer could not take in the full installation from one angle, consequently reinforcing the notion that an understanding of self and other cannot be limited to singular perspectives or categories. By staggering the panels of fabric and leaving space between them, there is an encouragement to move around and through the piece in order to fully view and comprehend all facets of the installation. The fabric

\footnotetext{
${ }^{76}$ See Figure 2.
} 
also moves and shifts as the audience moves through the panels, further emphasizing the themes of fluidity.

As this was the first iteration of my piece there was much to be learned from the experience. I had had no previous experience as an installation artist; thus, the gallery space and the translation of a flat video on a computer screen into a three-dimensional sculptural and optical piece involved a lot of obstacles and considerations that were very new to me as a filmmaker. One of the biggest findings was the quality of the image that I had been entirely editing on a monitor and was then projected on translucent fabric and a wall. Thus, the fidelity of the image and its colouring were lost at times becoming unreadable in some instances. ${ }^{77}$ For the future I think this can be addressed either saturating or exaggerating the contrast in the image so that the details of the image can be better seen. Additionally, situating the projectors was difficult for me to strategize effectively. In this type of configuration, the placement and angling of the projectors was incredibly important affecting where the image hits the fabric and the wall, and how well the image can then be read. One of these walls at Beaver Hall had wooden paneling, which, unfortunately drained the brightness from the image when it was projected, something I had not anticipated. As well, the angling of the projector, unfortunately, resulted in the image bleeding from the wall on to the floor. A solution to this that I had discussed with my supervisor would have been to ensure that each channel was projected on the three white walls available, thus allowing the image to be understood more easily. This would also move the video projections away from the

\footnotetext{
${ }^{77}$ See Figure 3.
} 
entrance (which was closest to the wooden wall) and thus avoid light leakage from the entrance and title wall of the gallery. 


\section{DOCUMENTARY RELEVANCE}

Through the process of creating this video installation I have looked at various other installations and films in order to inform and situate my work in a broader artistic context. My research has included a range of works, from traditional documentaries and experimental video art to installations observing how their form, style, and subject matter are relevant to my piece. In doing so I have been able to implement new techniques and strategies to strengthen my project, while understanding where my newfound research and knowledge belong in the gender discourse. One of the works I found in my research is a video art piece titled Identity Tides by Jane Winslow and Barbara Stout, presented in 2015. The installation was exhibited at Tyler Art Gallery in Oswego, and projects video footage of tidal waves over a portrait triptych of three participants, whom they term "gender-full" people. Audio from interviews with the subjects of the portraits plays through the gallery as they discuss how biological and social concepts of gender influence their lives. ${ }^{78}$ The piece has been informative to me in both form and subject matter. Similar to my own work the video installation discusses the fluidity of gender identity and uses interviews and personal experience in order to develop these concepts. While Strout and Winslow's work employs the metaphor of water as a commentary, I have used fabric as a physical component to evoke similar ideas of the changeability of gender. Identity Tides layers moving image over still image building deeper narratives about the subject matter through the merging of dissimilar visuals, which prompted me to pay attention to the particulars of my three-channels

\footnotetext{
${ }^{78}$ Jane Winslow, and Barbara Strout, Identity Tides, (2015: Tyler Art Gallery), video installation.
} 
and how it could enhance ideas about multi-faceted identity by being built up through the fragmentation and layering of various images.

In a similar vein of actively playing with perceptions of gender and external presentation through disembodied voice and video, I looked to another installation titled Communicating Vessels by Annie MacDonell and Maïder Fortuné, made in 2018 and exhibited at Gallery 44 in Toronto. The piece works with a similar technique that plays two video pieces depicting interactions between two women on separate TV screens, while the audio of an autobiographical fable plays throughout the gallery. In a separate room within the gallery is a projected video that shows the narrator of the fable speaking. ${ }^{79}$ This strategy had initially informed my intention to have interviews of my participants play separately from the visual footage presented. In both this piece and my own, finding the speaker becomes a payoff by later realizing who the story belongs to. Additionally, disembodied voice forces the audience to create new narratives based on the visual imagery presented, later having to be confronted with the physical presence of the speaker. When one is faced with the voice of an unknown narrator a fictitious image appears in one's mind making presumptions about the speaker's gender presentation and their voice. With this work in mind I began to carefully consider the position of gender non-conforming and trans peoples whose bodies become markers for how they are permitted to move through the world. Their voice and body becomes a site for judgement to interrogate how effectively they fit within the categories of either male or female. To present the viewer with a disembodied voice in a piece that

\footnotetext{
${ }^{79}$ Annie Macdonell, and Maïder Fortuné, Communicating Vessels, (2018: Gallery 44), video installation.
} 
specifically critiques gender binaries is to challenge their learned necessity to classify vastly unique characteristics of peoples.

Once realizing that fabric was the perfect medium to visualize notions of fluidity and ephemerality of existence, I turned to other works that dealt with fabric projection. Among them is the piece titled The Veiling by Bill Viola installed at the United States Pavilion of the Venice Bennale in 1995. The work utilizes nine sheer scrims that hang parallel to each other from the ceiling. Two projectors located on opposite ends of the scrims play images of a man and a woman that appear to be walking towards each other through the panels, eventually merging at the centre and slowly moving apart. ${ }^{80}$ These videos play on a loop, creating "a hypnotic effect when viewed and use light and transparency to evoke feelings of a dreamy trance." ${ }^{81}$ Much like in Viola's installation, the physical structuring of the multi-faceted human experience through fabric panelling has become a central part of my piece, capturing all of the themes discussed by my participants in an experiential way. Thus the medium becomes a method for reinforcement and enhancement so that the audience is not only captivated by the words spoken, but is also able to conceptually reflect on the thoughts and notions that are being shared.

To further build my consideration of projecting upon fabric I looked at the work Light Green Leaves with Light by Hyun Jean Lee, created in 2012. Lee takes silkscreen fabric as translucent paneling, on which to project a multi-channel video, consisting of

\footnotetext{
${ }^{80}$ Bill Viola, The Veiling, (1995: United States Pavilion), video installation.

81 "Bill Viola," The Fabric Workshop and Museum online, last modified 2011 http://www.fabricworkshopandmuseum.org/Artists/ArtistDetail.aspx?Artistld=8db57031-7ee0-48fa-ac7ae62e6ec16e95.
} 
images of trees and light as it filter through leaves; these overlap and pass through each layer of fabric. ${ }^{82}$ Both Viola's and Lee's pieces facilitate my consideration of using translucent materials in order to overlap images and experiment with how light passes through layers of material, lending itself to the notion of multiplicity and changeability. Where Lee's work differs from Viola's is in the way the fabrics are installed - at times parallel, at times perpendicular - and entirely staggered from one another. This operates totally differently to the structured uniformity found in Viola's paneling. By using Lee's technique, I have strengthened my message of multi-faceted and nonclassifiable identity allowing me to play with a lack of structure. Furthermore, staggering the fabric in this way allows the viewer to move through the work completely changing their relationship to the installation. The audience is no longer a distant observer; now they are involved in the work itself as their shadows become imprinted on the fabric and their positions become challenged by the conversations carried on by Cleo and Evelyn. In my own work three channels and projectors from the ceiling allows me to convey the feeling of embodiment, where I hope one feels the need to constantly move around and through the work finding new layers to consider and deconstruct, while always being aware of the real world implications at stake in the discussion.

I also spent time looking at the film Two Spirits: Sexuality, Gender, and the Murder of Fred Martinez (2009) by Lydia Nible. This documentary looks at cultural contexts behind the horrific death of Fred Martinez, a Navajo teenager, examining how his identity as a two-spirit individual was greatly celebrated by his community, despite

\footnotetext{
${ }^{82}$ Hyun Jean Lee, Light Green Leaves with Light, (2012), video installation.
} 
being the cause of his murder. Two Spirits attentively captures the balance of masculinity and femininity found in Fred, a feature of his identity that has long been embraced by Navajo traditions. The film's subject matter is of course on par with mine as it focuses on two-spirit identity; however, it greatly differs from my work through its focus on tragedy. ${ }^{83}$ Nonetheless, it is very important to be aware of, and in conversation with, the few films that have been made about Indigenous two-spirit identity. In particular, having learnt of this documentary, I find my work to be even more important in balancing Indigenous representation as something that is not always burdened by tragedy and pain.

${ }^{83}$ Lydia Nibley, Two Spirits: Sexuality, Gender, and the Murder of Fred Martinez (2009: Say Yes Quickly Productions), video. 


\section{CONCLUSION}

The Anishinaabe teachings from my participants Evelyn and Cleo make it evident that their two-spirit identity is a necessary part of their being, one that is interwoven into their daily existence and relationships. They share experiences of the traumas they've faced through illness and racially charged conflicts, but the overwhelming tone of the interviews suggests a complete acceptance of self, supported by family members, friends, and community, and while they face their own set of challenges they continue to live full and gratifying lives. ${ }^{84}$ I have also learned that this view of gender has similarly been understood in various populations around the world, and has changed within the West as well as is the nature of culture and human growth.

Moving forward with the experience I gained from this first iteration of All Kinds of People, All Kinds of Ways, I hope to present the work again in new galleries and settings. Through this thesis project I have come to learn how drastically installations, in particular, are altered dependent on their setting. I am looking forward to submitting the work to other galleries and discovering the new connotations and experiences that can be built from a different space. Each space would offer a unique set of optical and spatial challenges that I am interested in tackling. More importantly, I am hopeful for the conversations that may be prompted from the project and the reflections that may be considered.

Word count: 11,036

\footnotetext{
${ }^{84}$ Evelyn Pakinewatik, interview by Klasha Fernandes, August 10, 2018, interview, video.
} 


\section{BIBLIOGRAPHY}

Abrams, Mere "What Does It Mean to Identify as Nonbinary?." Healthline. Accessed August, 27, 2019.

https://www.healthline.com/health/transgender/nonbinary\#takeaway.

Alexander, Geoff. America Goes Hawaiian: The Influence of Pacific Island Culture on the Mainland. North Carolina: McFarland \& Company Inc., 2019.

"A Map of Gender-Diverse Cultures." PBS online. Last modified August 11, 2015. http://www.pbs.org/independentlens/content/two-spirits_map-html/.

Bigler, Rebecca, Amy Roberson Hayes, and Veronica Hamilton. "The Role of Schools in the Early Socialization of Gender Differences." Encyclopedia on Early Childhood Development online. Last modified August, 2014. http://www.childencyclopedia.com/gender-early-socialization/according-experts/role-schools-earlysocialization-gender-differences.

"Bill Viola." The Fabric Workshop and Museum online. Last modified 2011. http://www.fabricworkshopandmuseum.org/Artists/ArtistDetail.aspx?Artistld=8db5703 1-7ee0-48fa-ac7a-e62e6ec16e95.

Bucholtz, Mary. "Bad Examples: Transgression and Progress in Language and Gender Studies." In Reinventing Identities: The Gendered Self in Discourse, edited by Mary Bucholtz, A.C. Liang, and Laurel A. Sutton, 3-24. Oxford: Oxford University Press, 1999.

Bucholtz, Mary. "The Feminist Foundations of Language, Gender, and Sexuality Research." In The Handbook of Language, Gender, and Sexuality, 2nd Edition, edited by Susan Ehrlich, Miriam Meyerhoff, and Janet Holmes, 23-47. New York: Wiley Blackwell, 2014.

Butler, Judith. Gender Trouble: Feminism and the Subversion of Identity. New York: Routledge, 1990.

Butler, Judith. "Performative Acts and Gender Constitution." In The Feminism and Visual Culture Reader Second edition, edited by Amelia Jones, 482-492. New York: Routledge, 2010.

Bryson, Valerie. "Radical Feminism: Knowledge, Language and Patriarchy," In Feminist Political Theory, (1992): 222-231. doi: https://doi.org/10.1007/978-1-349-22284-1_13.

Cameron, Micelle. "Two-Spirited Aboriginal People: Continuing Cultural Appropriation by Non-Aboriginal Society." Canadian Woman Studies 24, no. 2 (2005): 123-127. 
Carver, Terrell. "Gender." In Political Concepts. edited by Richard Bellamy and Andrew Mason, 169-181. Manchester: Manchester University Press, 2003.

Chodorow, Nancy J. "Gender as a Personal and Cultural Construction." In Signs 7, no. 3 (1995): 516-544. https://www.jstor.org/stable/3174832.

Davies, Sharyn Graham. "What we can learn from an Indonesian ethnicity that recognizes five genders." The Conversation. Last modified June 16, 2016.

https://theconversation.com/what-we-can-learn-from-an-indonesian-ethnicity-thatrecognizes-five-genders-60775.

Dempsey, Hugh A. The Vengeful Wife and Other Blackfoot Stories. Norman: University of Oklahoma Press, 2014.

Elshtain, Jean Bethke. "Feminist Discourse and Its Dicontents: Language, Power, and Meaning." In Signs 7, no. 3 (1982): 603-621. https://www.jstor.org/stable/3173857.

Estrada, Gabriel S. "Two Spirits, Nádleeh, and LGBTQ2 Navajo Gaze." American Indian Culture and Research Journal 35: no. 4 (2011): 167-190.

Ibrahim, Farid M. "Homophobia and rising Islamic intolerance push Indonesia's intersex bissu priests to the brink." Australian Broadcasting Corporation News. Last accessed February 26, 2019. https://www.abc.net.au/news/2019-02-27/indonesia-fifth-gendermight-soon-disappear/10846570.

Faulstich Orellana, Marjorie. "Good Guys and "Bad" Girls: Identity Construction by Latina and Latino Student Writers." In Reinventing Identities: The Gendered Self in Discourse, edited by Mary Bucholtz, A.C. Liang, and Laurel A. Sutton, 64-82. Oxford: Oxford University Press, 1999.

Keahna, Cleo. Interview by Klasha Fernandes. August 3, 2018. Interview, video.

Kochems, Lee M., and Sue-Ellen Jacobs. "Gender Statuses, Gender Features, and Gender/ Sex Categories: New Perspectives on an Old Paradigm." In Two-spirit People: Native American Gender Identity, Sexuality, and Spirituality, edited by Sue-Ellen Jacobs, Wesley Thomas, and Sabine Lang, 255-265. Chicago: University of Illinois Press, 1997.

Lang, Sabine. "Various Kinds of Two-Spirit People: Gender Variance and Homosexuality in Native American Communities." In Two-spirit People: Native American Gender Identity, Sexuality, and Spirituality, edited by Sue-Ellen Jacobs, Wesley Thomas, and Sabine Lang, 100-119.Chicago: University of Illinois Press, 1997. 
LeBow, Diana. "Rethinking matriliny among the Hopi." In Women In Search of Utopia: Mavericks and Mythmakers, edited by Ruby Rohrlich, and Elaine Hoffman Baruch, 8-18. New York: Shocken Books, 1984.

Lee, Hyun Jean. Light Green Leaves with Light. 2012. Video installation.

Little, William. "Gender, Sex, and Sexuality." In Introduction to Sociology. Houston: Rice University Press, 2016.

Lynn, Susan, Kristie Walsdorf, Marie Hardin, and Brent Hardin. "Selling Girls Short: Advertising and Gender Images in Sports Illustrated for Kids." Women in Sport \& Physical Activity Journal 11, no. 2 (2002): 77-100.

Macdonell, Annie, and Maïder Fortuné. Communicating Vessels. 2018: Gallery 44. Video installation.

Matzner, Andrew. "'Transgender, queens, mahu, whatever': An Oral History from Hawai'I." In Intersections: Gender, History and Culture in the Asian Context, no. 6 (2001): 3-15.

Mcelhinny, Bonnie. "Theorizing Gender in Sociolinguistics and Linguistic Anthropology." In The Handbook of Language and Gender, edited by Janet Holmes, and Miriam Meyerhoff, 21-43. New York: Wiley Blackwell, 2003.

Miller, Eleanor M., and Carrie Yang Costello. "The Limits of Biological Determinism." American Sociological Review 66, no. 4 (2000): 592-598.

Nibley, Lydia. Two Spirits: Sexuality, Gender, and the Murder of Fred Martinez. 2009: Say Yes Quickly Productions. Video.

Pakinewatik, Evelyn. Interview by Klasha Fernandes. August 10, 2018. Interview, video.

Reddy, Gayatri. With Respect to Sex: Negotiating Hijra Identity in South Asia. Chicago: University of Chicago Press, 2010.

Semple, Neil. "Egerton Ryerson." The Canadian Encyclopedia. Last modified July 27, 2017. https://www.thecanadianencyclopedia.ca/en/article/egerton-ryerson.

Toland Frith, Katherine, and Barbara Mueller. Advertising and Societies: Global Issues. New York: Peter Lang Publishing, 2010.

"Two-Spirit Community." Re:searching for LGBTQ2S+ Health. Accessed August 19, 2019. https://lgbtqhealth.ca/community/two-spirit.php. 
Udry, J. Richard. "Biological Limits of Gender Construction." American Sociological Review 65, no. 3 (2000): 443-457.

Viola, Bill. The Veiling. 1995: United States Pavilion. Video installation.

West, Candace, and Don H. Zimmerman. "Doing Gender." In Gender and Society 1, no. 2 (1987): 125-151. http://www.jstor.org/stable/189945.

Wilson, Judith. "One Way or Another: Black Feminist Visual Theory." In The Feminism and Visual Culture Reader Second edition, edited by Amelia Jones, 19-23. New York: Routledge, 2010.

Winslow, Jane, and Barbara Strout. Identity Tides. 2015: Tyler Art Gallery. Video installation.

World Health Organization. Eliminating forced, coercive, and otherwise involuntary sterilization. Geneva: World Health Organization, 2014.

Zanghellini, Aleardo. "Sodomy Laws and Gender Variance in Tahiti and Hawai'i." In Laws 2, no. 2 (2013): 51-68. 